\title{
Stunting and Wasting Among Children 0-59 Months of Age in Zambézia and Nampula Provinces of Mozambique: An Assessment of Population-Based Survey Results Against Global Targets
}

\section{Ann F. Green ( $\sim$ ann.f.green@vumc.org )}

Vanderbilt University Medical Center, Vanderbilt Institute for Global Health

Carole J. Wilson

LAPOP at Vanderbilt University

\section{Lazaro Gonzalez-Calvo}

Friends in Global Health

\section{Leslie Pierce}

Vanderbilt University Medical Center, Vanderbilt Institute for Global Health

\section{Diana Quelhas}

UNICEF Mozambique - Avenida do Zimbabwe

Javier Rodriguez

UNICEF Mozambique - Avenida do Zimbabwe

\section{Marla Amaro}

Ministry of Health, Government of the Republic of Mozambique

\section{Simão Tomo}

Operational Investigation Committee, Zambézia (NIOZ), Government of the Republic of Mozambique

\section{Troy D. Moon}

Vanderbilt University Medical Center, Vanderbilt Institute for Global Health

\section{Research Article}

Keywords: Nutrition, Stunting, Wasting, Pediatric, Mozambique

Posted Date: August 19th, 2021

DOl: https://doi.org/10.21203/rs.3.rs-777930/v1

License: (1) This work is licensed under a Creative Commons Attribution 4.0 International License.

Read Full License 


\section{Abstract}

Background: The number of undernourished children worldwide has increased by 45 million since 1990 . In Mozambique, Zambézia and Nampula Provinces carry a heavy burden of infectious diseases, as well as high rates of stunting and wasting. Mozambique developed a Multisectoral Action Plan for the Reduction of Stunting (2011-2014) that aimed to reduce the national prevalence of stunting to $20 \%$ by 2020 , but little is documented of its impact on childhood stunting since the 2011 DHS survey.

Methods: Cross-sectional data from a population-based household-level survey was collected between February and July 2019, among heads of households $\geq 15$ years of age in Zambézia and Nampula Provinces. The survey tool was a 500-item questionnaire covering domains related to household health and economics, with a special emphasis on maternal and child health, nutrition and WASH and the collection of anthropometric measurements in children 0-59 months. Children were assessed for Stunting and Wasting according to the WHO Child Growth Standards. SurveyToGo software was used for developing the data collection form, gathering data on mobile devices and sending securely to a server. Descriptive statistics were calculated for continuous variables as median with interquartile range and for categorical variables as percentages. The significance level for all testing was two-sided, set at 0.05 .

Results: A total of 3,937 households were included in our analysis, including anthropometric measurements of 5,423 children under five. Nearly half $(45 \%, n=2,460)$ of all children assessed met the criteria for stunting, with a higher prevalence in Nampula Province $(51 \%, n=1,180)$ than Zambézia Province $(41 \%, n=1,280)$. Four percent of children met the criteria for wasting in both provinces with children aged 6-11-months having the highest wasting prevalence overall (7\%).

Conclusions: Based on survey results using highly standardized anthropometric measurement methods, these two provinces are on track to meet international 2025 targets for reduction in wasting in children under 5 years. However, stunting prevalence over time in both provinces has maintained at $40-50 \%$ with no clear evidence of decline since 2003. It is doubtful the related Sustainable Development Goal targets will be reached unless a focused multi-sectoral approach is employed and closely monitored.

\section{Background}

Despite global efforts to reduce childhood malnutrition in the world, the two common forms - stunting (chronic malnutrition defined as inadequate height for age) and wasting (acute malnutrition defined as inadequate weight for height/length) - remain a critical problem. The number of undernourished children worldwide has increased by 45 million since 1990, which is alarming given that malnutrition puts children at increased risk of dying from common infections and is associated with poor cognitive development that can negatively impact a country's long-term progress.(1-4) As of 2019, the global rate of stunting for children aged 0-59 months was estimated at $21.3 \%$, with Africa's stunting rate being nearly double this at $40 \%$. In contrast, the rate of wasting in Africa in 2019 was $6.4 \%$, slightly lower than the $6.9 \%$ reported 
globally. Overall, $27 \%$ of all wasted children live in Africa, and the number of stunted children continues to rise, likely reflecting the region's high population growth.(5-7)

In Mozambique, poor infrastructure and a weak economy have exacerbated child nutrition challenges. Based on the 2011 Demographic and Health Survey (DHS), stunting affected nearly one in every two children under the age of five years in Mozambique ( $43 \%$ overall, $46 \%$ in rural areas, $35 \%$ in urban), negatively impacting infant morbidity and mortality, school performance, and household income.(8) Zambézia and Nampula Provinces are among Mozambique's most populous provinces with a heavy burden of infectious diseases and rates of stunting ( $45 \%$ and $55 \%$ respectively) and wasting ( $3.7 \%$ and $8.4 \%$ respectively) above national averages, as reported in the 2015 Inquerito sobre Orçamento Familiar (IOF - National Family Budget Survey).(9)

Since 2011, few studies have been conducted in Mozambique that have assessed progress in childhood malnutrition. Two regional studies suggest that both stunting and wasting rates have declined over time, $(10,11)$ although potentially not enough to meet current targets outlined in the Sustainable Development Goals (SDG). (12)

In 2010, the Government of Mozambique developed the Multisectoral Action Plan for the Reduction of Chronic Malnutrition (2011-2014) that aimed to reduce the national prevalence of stunting to $20 \%$ by 2020.(6) One study assessed progress and identified strengths and weaknesses of plan implementation, but little is known in terms of its impact on childhood stunting since the 2011 DHS survey or 2015 IOF report. $(9,13)$ In 2009, the Mozambican Ministry of Health implemented a nutrition surveillance system based on a network of sentinel sites in district capitals that was intended to document and analyze the nutritional situation of the country to identify those at greatest risk.(14) However, a national review in 2014 suggested that due to the limited prevalence of acute malnutrition and the need to focus stakeholder attention on stunting, maintaining a continuous sentinel site nutrition surveillance system that cannot provide the representative monitoring of the nutrition situation needed for Mozambique, is not appropriate.(14) Instead, a representative surveillance system based on routine population-based surveys, with reliable measurement across representative samples, was felt to be more effective, given the Mozambican context.(14)

Per this recommendation, in order to gather baseline figures related to UNICEF's most recent 5-year multisectoral program to combat stunting and wasting in children under 5 years of age, our team implemented a population-based survey that focused on maternal and child health, nutrition and WASH indicators in two of Mozambique's most populous provinces with historically poor nutrition indicators. Due to Mozambique's previous challenges in attaining accurate reliable data for child anthropometric measurements, extra attention was paid to ensure a strong understanding of the survey, related data, and competency in data collection and management, especially with regards to accurately collecting anthropometric measurements.(14)

\section{Methods}


We used cross-sectional data from a population-based survey conducted between February and July 2019, collected as part of an evaluation of a Government program titled: "Improvement of the Nutritional Status of Children in Mozambique in the Provinces of Zambézia and Nampula". The unit of analysis for this study was the household $(\mathrm{HH})$ and only those with at least one child aged 0-59 month were included. Interviews were conducted with the head of household $(\mathrm{HoH})$, if $\geq 15$ years of age. Female HoHs were prioritized, but if no female $\mathrm{HoH}$ existed then a male $\mathrm{HoH}$ was surveyed. The $\mathrm{HoH}$ was asked questions about all children age 0-59 months who were present and who slept in any of the dwellings within the compound the night prior, as well as same age children who routinely shared food "from the same pot" as themselves. Anthropometric measurements (length/height,weight and mid upper arm circumference) were obtained for all eligible children identified, according to their age groups.

\section{Study Sites}

The survey was conducted in four intervention districts in Zambézia Province (Gurúè, Lugela, Molumbo, and Pebane), and three intervention districts in Nampula Province (Monapo, Nacala-a-Velha, and Ribáuè). Comparison Enumeration Areas (EA) from the remaining districts of each province (18 districts in Zambézia Province and 20 in Nampula Province) were selected for provincial-wide samples within both provinces (Figure 1).

\section{Sampling Frame}

The sampling frame for this survey relied on the 2017 Mozambique Population and Housing Census.(15) The Mozambican National Institute of Statistics (INE) provided cartographic maps from which EA boundaries were clearly indicated. Prior to survey implementation, we utilized the census data and cartographic maps to randomly select 196 EA in Zambézia Province (98 EA in the intervention districts and 98 EA throughout the rest of the Province) and 136 EA in Nampula Province (68 EA in the intervention districts and 68 EA throughout the rest of the Province). Identification of the boundaries of the randomly selected EAs was determined with the assistance of local leaders, cartographic maps, and by mapping GPS coordinates.

\section{Household Selection}

In EA with $\leq 200$ households, each household was counted and registered. Twelve households per EA were randomly selected using a randomization instrument for participation. In EA with $>200$ households, the EA was first divided into four geographic quadrants, followed by two quadrants being randomly chosen for household selection. We then randomly selected six households on the cartographic maps in each of the randomly selected quadrants to target for survey data collection. Households with no children aged 0-59 months were excluded and skipped. In eligible $\mathrm{HH}$, after the $\mathrm{HoH}$ agreed to participate, verbal and written informed consent was obtained. Interviews were conducted in the local language or in Portuguese, depending on the preference of the participant. The average length of interviews was ninety minutes. 


\section{Survey Tool}

The survey tool, developed by an interdisciplinary team of researchers, was a 500 -item questionnaire covering multiple dimensions and included questions borrowed from previous national surveys in Mozambique such as the DHS, Multiple Indicator Cluster Survey (MICS) and Ministry of Agriculture Technical Secretariat for Food Security and Nutrition (SETSAN) surveys. The survey was designed to gather information from the $\mathrm{HoH}$ on topics such as household demographics; economic status; health knowledge, attitudes, and practices; access to health services and products; access to improved water and sanitation; and had a special emphasis on nutrition, including breastfeeding, complimentary feeding, and food security. In addition to survey questions, an observation component mainly focused on the water and sanitation conditions was included.

\section{Anthropometric measurement}

Children's measurements were carried out following World Health Organization (WHO) recommendations for children's nutritional anthropometry.(16) All measurements were conducted by the survey team leaders (evaluators), who received extensive training on measuring height, weight and MUAC of children, as well as in identifying bilateral edema on their feet. Scales were calibrated prior to survey implementation with multiple rounds of tests conducted for consistency and measurement accuracy. Determining the age of the child in a standard way is important for correct use of anthropometric data. Official documents (personal identification card, child's health card), that were current and in actual use by the National Health System (SNS), were used to extract the child's exact date of birth when available, otherwise this was asked of the caregiver. Children under two years of age were weighed via a doublemeasurement process option on the scale, whereby the mother was weighed individually, and then weighed immediately after while holding the child, indirectly providing the weight of the child. Length/height for children was measured using standard altimeters approved by UNICEF. Children under two years of age were measured lying down (considered length), while children aged two and older were measured standing up (considered height). Additionally, children aged 6-59 months had their MUAC measured as an alternative method for assessing wasting. Special attention was given to ensure accuracy in recording anthropometric data, which was done by two people in a two-step process involving the evaluator recording her voice in the tablet while reading the measurement, then the interviewer writing it on the paper sheet, repeating it out loud to confirm and finally typing the measurements on the tablet. Then the interviewer and the evaluator compared the measurements with the respective reference table for the child's age and gender. If the value was outside the expected range, the team would repeat the measurements. Quality control of anthropometric data was conducted every two weeks, incorporating the Standardized Monitoring and Assessment of Relief and Transitions (SMART) methodology using the SMART ENA software.(17) The software evaluates the plausibility of data using 10 statistical tests that include an analysis of the distribution of anthropometric measures, randomness of measurement digit input, and the proportion of children in age and sex categories. The overall SMART score is $10 \%$ and is considered "Good". All tests were scored as "Excellent" except for the age ratio where there were a higher number of young children (6-29 months) in the sample than children 
30-60 months. Age ratio values are based on the program default values described in the SMART manual. While values may be typical for developing countries, we did not investigate the extent to which they accurately reflect the population of Mozambique.

\section{Survey Data Collection}

SurveyToGo software was used for developing the survey data collection form, gathering data on mobile devices (Samsung Tablet), and securely sending the data to a server. The project installed SurveyToGo on mobile devices for data entry and transmission to the survey team. Survey data was directly entered into the password-protected tablets by the data collectors and transmitted securely to the server over a cellular network or Wi-Fi.

\section{Data analysis}

Children were assessed for stunting and wasting according to the WHO Child Growth Standards. Children having a length/height-for-age $z$-score less than -2 were classified as stunted and those having a weightfor-length/height z-score less than -2 were classified as wasted. Each case of stunting and wasting was further categorized into moderate and severe (see table legends for definitions). Descriptive statistics were calculated for continuous variables as median with interquartile range and for categorical variables as percentages. The significance level for all testing was two-sided, set at 0.05. Stata 13.1 was used to analyze data collected from the survey instrument. Z-scores were obtained from the WHO Anthro Survey Analyzer Tool and imported into Stata.(18)

\section{Results}

A total of 3,984 households were planned for surveying, of which $99 \%(3,938)$ were successfully completed. One household was subsequently removed from analysis as the child's date of birth was not reported and there were no other children within that household. Ninety-three percent of interviews were conducted with a female $\mathrm{HoH}$. Of our 3,937 participating households, there were a total of 5,423 children aged 0-59 months identified living in those homes. The majority of adult respondents (92\%) were the child's biologic parent and gave birth to the child between the ages of 15 and 29 years. The number of male and female children was evenly split. A quarter of the children were under 11 months of age (25\%) and $42 \%$ of the children were being breastfed at the time of the survey. Just over half (53\%) of the children were born at a health center. Less than a tenth of the children were either underweight at birth (5\%), born with complications (8\%) or born via caesarean section (2\%) (Table 1). 
Table 1

Demographics of children aged 0-59 months living in participating households, Zambézia and Nampula Provinces

\begin{tabular}{|ll|}
\hline Characteristics N= 5,423 & $\mathbf{N}(\%)$ \\
\hline Gender & $2692(50 \%)$ \\
\hline Male & $2731(50 \%)$ \\
\hline Age & \\
\hline $0-5$ months & $646(12 \%)$ \\
\hline $6-11$ months & $697(13 \%)$ \\
\hline $12-23$ months & $1319(24 \%)$ \\
\hline $24-35$ months & $1115(21 \%)$ \\
\hline $36-47$ months & $923(17 \%)$ \\
\hline $48-59$ months & $723(13 \%)$ \\
\hline Currently Breastfeeding & \\
\hline Yes & $2259(42 \%)$ \\
\hline No & $3164(58 \%)$ \\
\hline Location of Delivery & \\
\hline At home & $2515(46 \%)$ \\
\hline Health Facility & $2853(53 \%)$ \\
\hline Other & $55(1 \%)$ \\
\hline Birth Conditions ${ }^{\text {a }}$ & \\
\hline Caesarean Birth & $286(5 \%)$ \\
\hline Had Complications at Birth & $435(8 \%)$ \\
\hline Underweight at Birth & \\
\hline
\end{tabular}

a Percentages are reported for respondents who indicated a "yes" response to separate questions and/or responses were part of a multiselect question. Therefore, percentages may sum to greater than or lesser than $100 \%$.

\section{Stunting and wasting}


Nearly half $(45 \%, n=2,460)$ of all children assessed were stunted, with a higher prevalence in Nampula Province $(51 \%, n=1,180)$ than Zambézia Province $(41 \%, n=1,280)$. Within Zambézia Province's intervention districts, Gurúè had the highest prevalence of stunting (51\%), followed by Pebane (40\%), Molumbo (40\%), and then Lugela (38\%). In Zambézia's comparison districts, $41 \%$ of children were stunted. In Nampula's intervention districts, stunting prevalence was highest in Monapo (57\%) followed by Ribáuè (54\%), and Nacala-A-Velha (46\%). In Nampula's comparison districts, $48 \%$ of children were stunted. Overall, the program intervention districts of both provinces combined had a slightly higher percentage of children with stunting than control districts at baseline ( $47 \%$ vs. $44 \%)$. When evaluated by age group, more than half of children aged $24-35$ months (56\%) and 36-47 months (50\%) had documented stunting (Table 2). 
Table 2

Stunting, by severity classification, as measured by length/height for age of children 0-59 months old

\begin{tabular}{|c|c|c|c|c|}
\hline & $\begin{array}{l}\text { Total }^{\mathrm{a}} \\
(\mathrm{N}=5,423)\end{array}$ & $\begin{array}{l}\text { Stunting* } \\
\mathrm{n}(\%)\end{array}$ & $\begin{array}{l}\text { Moderate stunting** } \\
\mathrm{n}(\%)\end{array}$ & $\begin{array}{l}\text { Severe stunting*** } \\
\mathrm{n}(\%)\end{array}$ \\
\hline Overall & 5,423 & $2,460(45 \%)$ & $1,549(29 \%)$ & $911(17 \%)$ \\
\hline Zambézia Province & 3,091 & $1,280(41 \%)$ & $854(28 \%)$ & $426(14 \%)$ \\
\hline Gurúè & 371 & $188(51 \%)$ & $98(26 \%)$ & $90(24 \%)$ \\
\hline Lugela & 366 & $140(38 \%)$ & $116(32 \%)$ & $24(7 \%)$ \\
\hline Pebane & 467 & $186(40 \%)$ & $140(30 \%$ & $46(10 \%)$ \\
\hline Molumbo & 333 & $132(40 \%)$ & $72(22 \%)$ & $60(18 \%)$ \\
\hline All other districts & 1,554 & $634(41 \%)$ & $428(28 \%)$ & $206(13 \%)$ \\
\hline Nampula Province & 2,332 & $1,180(51 \%)$ & $695(30 \%)$ & $485(21 \%)$ \\
\hline Monapo & 395 & $226(57 \%)$ & $133(34 \%)$ & $92(24 \%)$ \\
\hline Nacala-A-Velha & 325 & $151(46 \%)$ & $90(28 \%)$ & $61(19 \%)$ \\
\hline Ribáuè & 434 & $233(54 \%)$ & $140(32 \%)$ & $93(21 \%)$ \\
\hline All other districts & 1,178 & $570(48 \%)$ & $332(28 \%)$ & $238(20 \%)$ \\
\hline \multicolumn{5}{|l|}{ Study arms } \\
\hline Intervention districts & 2,691 & $1,256(47 \%)$ & $789(29 \%)$ & $467(17 \%)$ \\
\hline Non-intervention districts & 2,732 & $1,204(44 \%)$ & $760(28 \%)$ & $444(16 \%)$ \\
\hline \multicolumn{5}{|l|}{ Gender } \\
\hline Male & 2,692 & $1,291(48 \%)$ & $776(29 \%)$ & $515(19 \%)$ \\
\hline Female & 2,731 & $1,169(43 \%)$ & $773(28 \%)$ & $396(15 \%)$ \\
\hline \multicolumn{5}{|l|}{ Age } \\
\hline $0-5$ months & 646 & $142(22 \%)$ & $93(14 \%)$ & $49(8 \%)$ \\
\hline $6-11$ months & 697 & $230(33 \%)$ & $159(23 \%)$ & $71(10 \%)$ \\
\hline $12-23$ months & 1,319 & $640(49 \%)$ & 387 (29\%) & $253(19 \%)$ \\
\hline 24-35 months & 1,115 & $628(56 \%)$ & 372 (33\%) & $256(23 \%)$ \\
\hline 36-47 months & 923 & $466(50 \%)$ & 304 (33\%) & $162(18 \%)$ \\
\hline $48-59$ months & 723 & 354 (49\%) & $234(32 \%)$ & $120(17 \%)$ \\
\hline
\end{tabular}


${ }^{*}$ Children are defined as stunted if their length/height-for-age Z score is below - 2 SD the WHO Child Growth Standards median

${ }^{\star *}$ Children are defined as moderately stunted if their length/height-for-age Z score is below -2 SD \& above or equal to -3 SD the WHO Child Growth Standards median

${ }^{* * *}$ Children are defined as severely stunted if their length/height-for-age Z score is below -3 SD the WHO Child Growth Standards median

aTotals represent all child participants, including those with no evidence of malnutrition, thus percentages per line may not add up to $100 \%$.

Overall, of the children assessed using the weight-for- length/ height method, $4 \%$ were wasted. When analyzing the severity of wasting, $3 \%$ were moderately wasted and $1 \%$ were severely wasted. The percentages for each threshold were identical between Zambézia and Nampula at the provincial level (4\% wasting, $3 \%$ moderate wasting, $1 \%$ severe wasting). Differences in proportions of wasting were seen between age categories. Children in the 6 to 11-month age group had the highest prevalence of wasting (7\%) with moderate and severe wasting percentages for this population being $5 \%$ and $2 \%$, respectively. Wasting (5\%) prevalence was also high among the $0-5$ month and 12-23-month age categories and differed only slightly by the sex of the child ( $5 \%$ male vs. $3 \%$ female) (Table 3 ). 
Table 3

Wasting, by severity classification, as measured by weight for length/height of children 0-59 months old

\begin{tabular}{|c|c|c|c|c|}
\hline & $\begin{array}{l}\text { Total }^{\mathrm{a}} \\
(\mathrm{N}=5,398)\end{array}$ & $\begin{array}{l}\text { Wasting* } \\
\text { n (\%) }\end{array}$ & $\begin{array}{l}\text { Moderate wasting** } \\
\mathrm{n}(\%)\end{array}$ & 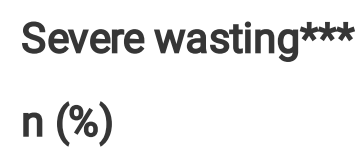 \\
\hline Overall & 5,398 & $216(4 \%)$ & $165(3 \%)$ & $51(1 \%)$ \\
\hline Zambézia Province & 3,075 & $122(4 \%)$ & $99(3 \%)$ & $23(1 \%)$ \\
\hline Gurúè & 370 & $14(4 \%)$ & $10(3 \%)$ & $4(1 \%)$ \\
\hline Lugela & 365 & $17(5 \%)$ & $12(3 \%)$ & $5(1 \%)$ \\
\hline Pebane & 465 & $20(4 \%)$ & $16(3 \%)$ & $4(1 \%)$ \\
\hline Molumbo & 333 & $16(5 \%)$ & $14(4 \%)$ & $2(1 \%)$ \\
\hline All other districts & 1,542 & $55(4 \%)$ & $47(3 \%)$ & $8(1 \%)$ \\
\hline Nampula Province & 2,323 & $94(4 \%)$ & $66(3 \%)$ & $28(1 \%)$ \\
\hline Monapo & 395 & $7(2 \%)$ & $7(2 \%)$ & $0(0 \%)$ \\
\hline Nacala-A-Velha & 324 & $27(8 \%)$ & $16(5 \%)$ & $11(3 \%)$ \\
\hline Ribáuè & 434 & $20(5 \%)$ & $14(3 \%)$ & $6(1 \%)$ \\
\hline All other districts & 1,170 & $40(3 \%)$ & $29(2 \%)$ & $11(1 \%)$ \\
\hline \multicolumn{5}{|l|}{ Study arms } \\
\hline Intervention districts & 2,686 & $121(5 \%)$ & $89(3 \%)$ & $32(1 \%)$ \\
\hline Non-intervention districts & 2,712 & $95(4 \%)$ & $76(3 \%)$ & $19(1 \%)$ \\
\hline \multicolumn{5}{|l|}{ Gender } \\
\hline Male & 2,684 & $123(5 \%)$ & $93(3 \%)$ & $30(1 \%)$ \\
\hline Female & 2,714 & $93(3 \%)$ & $72(3 \%)$ & $21(1 \%)$ \\
\hline \multicolumn{5}{|l|}{ Age } \\
\hline $0-5$ months & 637 & $32(5 \%)$ & $22(3 \%)$ & $10(2 \%)$ \\
\hline 6-11 months & 695 & $50(7 \%)$ & $37(5 \%)$ & $13(2 \%)$ \\
\hline $12-23$ months & 1,313 & $71(5 \%)$ & $54(4 \%)$ & $17(1 \%)$ \\
\hline $24-35$ months & 1,110 & $30(3 \%)$ & $29(3 \%)$ & $1(0 \%)$ \\
\hline $36-47$ months & 921 & $32(2 \%)$ & $14(2 \%)$ & $7(1 \%)$ \\
\hline $48-59$ months & 722 & $23(2 \%)$ & $9(1 \%)$ & $3(0 \%)$ \\
\hline
\end{tabular}


${ }^{*}$ Children are defined as wasted if their weight-for-length/height Z score is below - 2 SD the WHO Child Growth Standards median

${ }^{*}$ Children are defined as moderately wasted if their weight-for-length/height Z score is below -2 SD \& above or equal to -3 SD the WHO Child Growth Standards median

${ }^{\star * \star}$ Children are defined as severely wasted if their weight-for-length/height Z score is below -3 SD the WHO Child Growth Standards median

a Totals represent all child participants, including those with no evidence of malnutrition, thus percentages per line may not add up to $100 \%$.

Of the children 6 to 59 months of age assessed for acute malnutrition using the MUAC method, $5 \%$ were wasted, with $3 \%$ being classified as moderately, and $1 \%$ being classified as severely wasted. Prevalence of wasting by MUAC was slightly but consistently lower in Zambézia as compared to Nampula ( $5 \%$ vs. $6 \%$ wasting, $3 \%$ vs. $4 \%$ moderate, $1 \%$ vs. $2 \%$ severe wasting respectively). Differences in MUAC measurements were seen between age categories: children in the 6 to 11-month age group still had the highest prevalence of wasting (12\%), with $8 \%$ having moderate wasting and $4 \%$ severe wasting. Wasting was also high among the 12-23-month age category (5\%). No major differences were seen by the sex of the child (Table 4). 
Table 4

Wasted, by severity classification, as measured by mid-upper arm circumference of children 6-59 months old

\begin{tabular}{|c|c|c|c|c|}
\hline & $\begin{array}{l}\text { Total }^{\mathrm{a}} \\
(\mathrm{N}=4,777)\end{array}$ & $\begin{array}{l}\text { Wasting* } \\
\text { n (\%) }\end{array}$ & $\begin{array}{l}\text { Moderate wasting** } \\
\text { n (\%) }\end{array}$ & 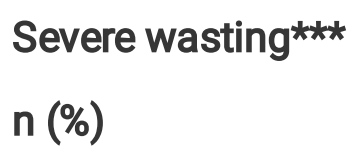 \\
\hline Overall & 4,777 & $239(5 \%)$ & $161(3 \%)$ & $66(1 \%)$ \\
\hline Zambézia Province & 2,747 & $125(5 \%)$ & $84(3 \%)$ & $34(1 \%)$ \\
\hline Gurúè & 337 & $15(4 \%)$ & $9(3 \%)$ & $6(2 \%)$ \\
\hline Lugela & 321 & $17(5 \%)$ & $12(4 \%)$ & $4(1 \%)$ \\
\hline Pebane & 407 & $17(4 \%)$ & $11(3 \%)$ & $6(1 \%)$ \\
\hline Molumbo & 288 & $14(5 \%)$ & $8(3 \%)$ & $6(2 \%)$ \\
\hline All other districts & 1,394 & $64(5 \%)$ & $44(3 \%)$ & $12(1 \%)$ \\
\hline Nampula Province & 2,030 & $112(6 \%)$ & $77(4 \%)$ & $32(2 \%)$ \\
\hline Monapo & 353 & $21(6 \%)$ & $16(5 \%)$ & $5(1 \%)$ \\
\hline Nacala-A-Velha & 270 & $21(8 \%)$ & $17(6 \%)$ & $4(1 \%)$ \\
\hline Ribáuè & 380 & $8(2 \%)$ & $3(1 \%)$ & $5(1 \%)$ \\
\hline All other districts & 1,027 & $62(6 \%)$ & $41(4 \%)$ & $18(2 \%)$ \\
\hline \multicolumn{5}{|l|}{ Study arms } \\
\hline Intervention districts & 2,356 & $113(5 \%)$ & $76(3 \%)$ & $36(2 \%)$ \\
\hline Non-intervention districts & 2,421 & $126(5 \%)$ & $85(4 \%)$ & $30(1 \%)$ \\
\hline \multicolumn{5}{|l|}{ Gender } \\
\hline Male & 2,385 & 108 (5\%) & $68(3 \%)$ & $35(1 \%)$ \\
\hline Female & 2,392 & $131(5 \%)$ & $93(4 \%)$ & $31(1 \%)$ \\
\hline \multicolumn{5}{|l|}{ Age } \\
\hline $6-11$ months & 697 & $86(12 \%)$ & $55(8 \%)$ & $29(4 \%)$ \\
\hline $12-23$ months & 1319 & $100(8 \%)$ & $71(5 \%)$ & $25(2 \%)$ \\
\hline 24-35 months & 1115 & $35(3 \%)$ & $25(2 \%)$ & $6(1 \%)$ \\
\hline $36-47$ months & 923 & $11(1 \%)$ & $6(1 \%)$ & $4(<1 \%)$ \\
\hline $48-59$ months & 723 & $7(1 \%)$ & $4(1 \%)$ & $2(<1 \%)$ \\
\hline
\end{tabular}

*Children are defined as wasted if their MUAC $<115 \mathrm{~mm}$ 
${ }^{\star *}$ Children are defined as moderately wasted if their MUAC $<115 \mathrm{~mm} \& \geq 125 \mathrm{~mm}$

${ }^{\star \star *}$ Children are defined as severely wasted if their MUAC $<125 \mathrm{~mm}$

${ }^{a}$ Totals represent all child participants, including those with no evidence of malnutrition, thus percentages per line may not add up to $100 \%$.

In order to evaluate progress over time for Zambézia and Nampula Provinces with regards to stunting and wasting prevalence, we compared our results with similar population-based studies done in the past, as well as the targeted goals promoted by the WHO/UNICEF Maternal, Infant and Young Child (MIYC) nutrition targets first established for 2025 and later partially incorporated into the Sustainable Development Goals (SDGs) for 2030.(8,10)(19) For purposes of comparisons between surveys, we will consider only wasting as measured by weight-for-length/height, and not MUAC, as this is currently the standard method used for population based surveys. In general, since 2003 , both provinces have seen a gradual decline in the reported prevalence of wasting, with Zambézia Province already meeting the 2025 MIYC target of 5\% as of 2014 and Nampula being very close with a $6 \%$ prevalence reported here for 2019. The 2030 SDG target for wasting was set at eliminating all forms of malnutrition, and a WHO discussion paper later recommended an adjusted, regionally tailored operational SDG target of less than $3 \%$ wasting prevalence by 2030 (Fig. 2).(19)

With regards to the prevalence of stunting over time, both provinces have maintained a reported prevalence of roughly $40-50 \%$ with no clear evidence of decline since 2003. Established targets for stunting prevalence for the 2025 MIYC are set at $14.7 \%$ with a further desired decrease to $7 \%$ by 2030 under the operational SDG target and elimination per the SDG target (Fig. 3).

\section{Discussion}

In this study we set out to describe the current nutritional state of children under five years of age in Zambézia and Nampula Provinces, Mozambique, as a baseline evaluation at the beginning of a new multisectoral Government program with the objective to reduce stunting and wasting in these provinces and age groups and to describe this region's progress in child nutrition overtime, comparing our results with prior population-based surveys completed in the area since 2003.

Since the 1970's the global health community at large has attempted to address the poor nutritional statistics seen in certain parts of the world, with various intervention programs being undertaken in the world's most undernourished regions.(20-23) The United Nations, WHO, Food and Agriculture Organization, United States Agency for International Development and a vast number of international partners and governments sought out solutions and targets to eliminate malnutrition. One of the more widely known set of global goals and targets toward ending a range of international development challenges are the eight Millennium Development Goals (MDGs), agreed upon by world leaders at the 2000 United Nations summit, which included goals to end hunger and reduce the under-five mortality rate by two-thirds from 1990-2015.(24-26,7) While important progress was made under the MDG initiative, 
such as a nearly $50 \%$ drop in the proportion of undernourished people in the developing world from 1990-2014, it is still widely held that the MDGs had some significant gaps, which include the fact that the nutrition indicator did not include a target for stunting or wasting.(27-30)

At the end of the MDG target period there were still roughly 800 million people living in extreme poverty, suffering from hunger, and over 160 million children under age five were stunted.(24) According to UNICEF, one unintended consequence of setting the MDGs broad global goals was that they had inadvertently encouraged the measurement of progress through national averages. In a push to meet the outlined targets, many nations focused on the most accessible children and communities, instead of those in greatest need, which in turn may have actually slowed national progress.(31) More recent evidence has shown that investment in an equity-focused approach for child health can accelerate results in a cost-effective manner.(32) Moreover, the fact that the MDGs failed to specify how to achieve the identified nutritional targets, hampered individual country-level ownership of the goals.(30)

These shortcomings were subsequently targeted in the 2015 United Nations General Assembly that ratified the SDGs, which included two of the MIYC Nutrition 2025 global targets. The second SDG included two specific nutrition-related targets to reach by 2030: 1) to end hunger and ensure access by all people to safe, nutritious and sufficient food all year round and 2) to end all forms of malnutrition by 2025 , through the internationally agreed targets on stunting and wasting in children under 5 years of age, and to address the nutritional needs of adolescent girls, pregnant and lactating women and older persons.(33) According to the recent 2019 SDG progress report the world is not on track to meet the nutrition targets for the SDGs, and two thirds of undernourished people worldwide live in sub-Saharan Africa and southern Asia.(1)

Lessons learned from the MDG framework specific to nutrition include the realization that the focus on malnutrition was too narrow, and that synergies between nutrition and other sectors were underexploited. For example, many national nutrition strategies in the 2000s focused almost exclusively on treatment of wasting. Anchored in ministries of health, these strategies often did little to encourage food-based approaches to reducing malnutrition. In many countries, the disconnect was further exacerbated by food security policies whose primary objective was increased production of staple grains.(3) Today, in contrast, a huge body of knowledge exists on "multi-sectoral approaches", including holding the food and agriculture sectors accountable for nutrition.(4) It is important to note that the "uni-sectoral" approach which fragmented nutrition strategies in the 2000s not only limited progress toward the achievement of MDG-1 targets, but probably also slowed progress in achieving other related targets such as educational attainment, child mortality and maternal health [5]. While we recognize that wasting is an acute condition, and as such, difficult to measure tendencies over time, our results indicate that Zambézia and Nampula Provinces have virtually met the 2025 target for wasting. In order to meet the 2030 SDG target for wasting the region will need to remain consistent with gains from existing interventions, perhaps increasing accountability of implementation coverage.(14) 
Stunting results for Zambézia and Nampula Provinces show less success over time and reaching the 2025 MIYC target or the 2030 SDG under present circumstances remains daunting. Stunting rates in these two provinces are roughly three times the desired target to be reached by 2025 , and a stronger, multi-faceted coalition of intervention activities will be necessary to have a significant impact. The Lancet's 2008 series on maternal and child malnutrition generated consensus among experts on a package of effective nutrition-focused interventions to address the leading causes of malnutrition.(34) Interventions that had the largest impact on stunting included food supplementation, zinc supplementation, general nutrition interventions, micronutrient supplementation, and conditional cash transfers. However, it is important to note that these were dependent upon at least $99 \%$ coverage for each intervention (or 70-90\% coverage for all interventions together), and historically monitoring of project implementation has proven to be a challenge, especially in Mozambique.(7,14,22,28,35,36) While the bulk of the recommended nutrition interventions have been introduced on some level in Mozambique, often they remain to be implemented on a sufficiently large scale to make a difference. $(19,22)$

Strengths of this study include its large sample size and study design that was representative of our two provinces. Survey interviewers were residents of the two provinces that administered the surveys in local languages known to the participants. Additional strengths include the quality assurance measures implemented to ensure the accuracy of our anthropometric measurement collection. Study limitations include the cross-sectional baseline survey design, which limits the level of inference into our results. Participants will not be tracked over time, so tracing a causal impact from this program's activities over time will not be possible. In addition,

the degree of implementation in terms of activity exposure and the precise locations of activities within beneficiary districts were not tracked at the time of this evaluation for this program's activities or those of other government and non-governmental partners operating in the districts and provinces targeted by the study.

\section{Conclusions}

Based on results of thorough anthropometric measurement within Zambézia and Nampula Provinces of Mozambique, these provinces are on track to meet international 2025 wasting targets for children under 5 years. However, the rate of stunting in the same population is still alarmingly high, such that it is doubtful the related SDG targets will be reached unless a focused multi-sectoral approach is employed. With this baseline survey, there is an opportunity to track intervention coverage and the degree of implementation fidelity in accordance with outlined intervention recommendations and gauge the impact on wasting and stunting over time.

\section{Abbreviations}

EAs - Enumeration Areas 
INE - Instituto Nacional de Estatistica (Mozambique's National Statistical Institute)

MDGs - Millennium Development Goals

SDGs - Sustainable Development Goals

SMART - Standardized Monitoring and Assessment of Relief and Transitions

UNICEF - United Nations Children's Fund

\section{Declarations}

Ethics approval and consent to participate

Ethics review and approval was provided by the Mozambican National Bioethics Committee for Health (Comité Nacional de Bioética para Saúde, CNBS) under protocol number 546/CNBS/18 and the Vanderbilt University Institutional Review Board (IRB) under protocol IRB \#182332.

Consent for publication

\section{Not applicable.}

Availability of data and materials

The datasets generated and/or analyzed during the current study are available in the Vanderbilt StarBrite Rocket repository, https://rocket.app.vumc.org/index.php?doc_id=31237, and external access is available from the corresponding author on reasonable request.

\section{Competing interests}

The authors declare that they have no competing interests.

\section{Funding}

This survey was funded by UNICEF Mozambique and the European Union. The UNICEF Mozambique team participated in the design of the study, training of data collectors, interpretation of data and in editing and revising this manuscript.

\section{Authors' contributions}

AG contributed to survey design, managed survey implementation and spearheaded the writing of this manuscript. CJW conducted the routine SMART dataset analysis and analyzed all survey data. LGC was a key contributor to survey design, led all in-country operations related to survey implementation, and played a strong role in data interpretation. LP assisted data interpretation and writing of the final survey report. DQ and JR played a key role in surveyor training and supervision for random household selection 
and anthropometric measurement as well as data interpretation and in editing and revising this manuscript. TM contributed heavily to survey design, assisted management of implementation, data interpretation and was a major contributor in writing the manuscript. All authors read and approved the final manuscript.

\section{Acknowledgements}

Survey design: Troy D. Moon, Ann F. Green, Lazaro González-Calvo, James McQuen-Patterson, Mathieu Joyeux, Diana Quelhas, Javier Rodriguez, Tomas Zaba and Zlata Bruckauf.

Instrument/ technology design: Facundo Salles, Sebastian Larrea (LAPOP).

Survey implementation Operations, Logistics and Finance: Marcia Souza, Manuela Ausse, Thomas Bonnet, Bernardo Matitimel, Zeca Marques, Tatiana Voloh, Jacinto Fumo, Basílio Damião

Survey Team Leaders/ Interviewers: Fernanda Alfinete, Sheila Jamonsin dos Santos, Domingas Osório Fulano, Estefania Antonio Valua, Katia L. Elias Formiga, Nafisa Omar J. Jalilo, Ancha Abdala Cassimo, Shamim Jalilo, Regina Margarida A. Muando, Eunice Francisco Pililão, Ihominio de Ndozanae Souza, Amina Issufo, Ana Paula Maricoa, Dulce de Angelina Alves Repossola, Guilda Zimba, Hortencia da Vânia Morgado, Fatima Luis Francisco Julião, Matilde Carlos Uaricalai, Latia Abdul Sacur Ambrósio, Elizabete dos Santos Augusto, Rosimer Julinha Félix Bange, Sónia Manuela da Silveira Azevedo, Urcilia Felicia Ronda Salvador, Ema Abílio Miguel, Ana Clarice Infuta, Judite Militão Laimo, Dina Militão Laimo, Edith Calage, Isabel Francisco Sicola, Chaquila Mussa Passades Ismael, Merci Eulalia Huber, Esmenia Antonio Mangachaia, Flora Tomas Antonio, Fernanda João Jakson, Noemia Margarida Azevedo, Maria Amelia José, Ilda Manecas Gravata, Mónica Antonio Mangachaia, Ines Francisco Machanisse, Ullstenia Jaime Nachicumba..

Special thanks to:

Maputo: Dra. Marla Amaro, Chief of the MOH's Nutrition Deparment (MISAU), Dra. Reka M. Cane, National Institute Health Research Department, Dino Buene, M\&E SETSAN, Javier Rodriguez, Nutrition Specialist, UNICEF, Tomas Zaba, M\&E UNICEF, Dr. Arão Balate, Deputy Director of Census at National Statistics Office, Dr. Basílio Cubula, Deputy Chief of Sampling at Methodology Department, Hermenegildo Mazivila and Charles, National Cartography \& Maps Department Office.

Zambezia: Dr. Hidayat Kassim, Provincial Director Health (DPSZ), Dr. Simão Tomo, Operational Investigation Committee (NIOZ), Dra. Benilde Ercilia, Manager Maternal \& Child Health Program (DPSZ), Dr. Assane Sail Namicano, Manager Nutrition Program (DPSZ), Isabel Oliveira, SETSAN Dr. Carlos Mafigo, UNICEF, Roberto Segredo, WASH Department and Dr. Armando Terenha, Deputy INE.

Nampula: Dra. Munira Bin Abudou, Provincial Director Health (DPSN), Dr. Artur Muloliwua, Operational Investigation Committee of DPS (NION), Dra. Ausentina Biombe, Manager Maternal \& Infant Health Program (DPSN), Dr. Malverno Inácio Sueleque, Manager Nutrition Program (DPSN), Higinio André, 
SETSAN, Dr. Vascos Muatecalene, UNICEF, Daniel Massinque, WASH Department and Dra. Teresa Pinto, Deputy INE.

\section{References}

1. - SDG Indicators [Internet]. [cited 2020 Apr 22]. Available from: https://unstats.un.org/sdgs/report/2019/

2. Trehan I, Bassat Q. The Unbearable Lightness of Being Malnourished: Severe Acute Malnutrition Remains a Neglected Tropical Disease. J Trop Pediatr. 2018 01;64(3):169-73.

3. Vollmer S, Harttgen K, Subramanyam MA, Finlay J, Klasen S, Subramanian SV. Association between economic growth and early childhood undernutrition: evidence from 121 Demographic and Health Surveys from 36 low-income and middle-income countries. Lancet Glob Health. 2014 Apr 1;2(4):e225-34.

4. Victora CG, Adair L, Fall C, Hallal PC, Martorell R, Richter L, et al. Maternal and child undernutrition: consequences for adult health and human capital. The Lancet. 2008 Jan 26;371(9609):340-57.

5. UNICEF/WHO/The World Bank Group joint child malnutrition estimates: levels and trends in child malnutrition: key findings of the 2020 edition [Internet]. [cited 2020 Apr 6]. Available from: https://www.who.int/publications-detail/jme-2020-edition

6. Emmanuel Skoufias Katja Vinha Ryoko Sato. All Hands On Deck: Reducing Stunting through Multisectoral Efforts in Sub-Saharan Africa [Internet]. The World Bank; 2019 [cited 2020 Apr 14]. 192 p. (Africa Development Forum). Available from: https://elibrary.worldbank.org/doi/book/10.1596/978-1-4648-1396-2

7. Mozambique: Nutrition Profile [Internet]. 2019 [cited 2020 Apr 20]. Available from: https://www.usaid.gov/global-health/health-areas/nutrition/countries/mozambique-nutrition-profile

8. The DHS Program - Mozambique: Standard DHS, 2011 [Internet]. [cited 2020 Apr 22]. Available from: https://www.dhsprogram.com/what-we-do/survey/survey-display-362.cfm

9. Castigoa F, Salvucci V. Estimativas e Perfil da Pobreza em Moçambique: Uma Analise Baseada no Inquérito sobre Orçamento Familiar - IOF 2014/15. Mozambique; 2016.

10. Rose ES, Blevins M, González-Calvo L, Ndatimana E, Green AF, Lopez M, et al. Determinants of undernutrition among children aged 6 to 59 months in rural Zambézia Province, Mozambique: results of two population-based serial cross-sectional surveys. BMC Nutr. 2015 Dec 17;1(1):41.

11. Pedrini M, Moraleda C, Macete E, Gondo K, Brabin BJ, Menéndez C. Clinical, nutritional and immunological characteristics of HIV-infected children in an area of high HIV prevalence. J Trop Pediatr. 2015 Aug;61(4):286-94.

12. Transforming our world: the 2030 Agenda for Sustainable Development | Department of Economic and Social Affairs [Internet]. [cited 2021 Mar 9]. Available from: https://sdgs.un.org/2030agenda

13. Michaud-Létourneau I, Pelletier DL. Perspectives on the coordination of multisectoral nutrition in Mozambique and an emerging framework. Food Policy. 2017 Jul 1;70:84-97. 
14. Analysis of the Sentinel Site Nutrition Surveillance System in Mozambique | Food and Nutrition Technical Assistance III Project (FANTA) [Internet]. [cited 2020 Apr 23]. Available from: https://www.fantaproject.org/countries/mozambique/sentinel-site-nutrition-surveillance-system

15. RGPH 2017 - Instituto Nacional de Estatistica [Internet]. [cited 2020 Apr 17]. Available from: http://www.ine.gov.mz/operacoes-estatisticas/censos/censo-2007/censo-2017

16. Growth Charts - WHO Child Growth Standards [Internet]. 2019 [cited 2020 Apr 22]. Available from: https://www.cdc.gov/growthcharts/who_charts.htm

17. ENA Software for SMART [Internet]. SMART Methodology. [cited 2021 Mar 9]. Available from: https://smartmethodology.org/survey-planning-tools/smart-emergency-nutrition-assessment/

18. WHO I The WHO Anthro Survey Analyser [Internet]. WHO. World Health Organization; [cited $2021 \mathrm{Mar}$ 9]. Available from: http://www.who.int/nutgrowthdb/software/en/

19. WHO/UNICEF discussion paper: The extension of the 2025 maternal, infant and young child nutrition targets to 2030 [Internet]. UNICEF DATA. 2019 [cited 2020 Apr 22]. Available from: https://data.unicef.org/resources/who-unicef-discussion-paper-nutrition-targets/

20. Fanzo J. Does Global Goal Setting Matter for Nutrition and Health? AMA J Ethics. 2018 Oct 1;20(10):979-86.

21. Parlesak A, Geelhoed D, Robertson A. Toward the prevention of childhood undernutrition: diet diversity strategies using locally produced food can overcome gaps in nutrient supply. Food Nutr Bull. 2014 Jun;35(2):191-9.

22. Picolo M, Barros I, Joyeux M, Gottwalt A, Possolo E, Sigauque B, et al. Rethinking integrated nutritionhealth strategies to address micronutrient deficiencies in children under five in Mozambique. Matern Child Nutr. 2019;15 Suppl 1:e12721.

23. Mid-term Review of the UN Decade of Action on Nutrition / United Nations [Internet]. [cited 2020 Apr 20]. Available from: https://www.un.org/nutrition/about/mid-term-review-un-decade-action-nutrition

24. United Nations Millennium Development Goals [Internet]. United Nations; [cited 2020 Apr 2]. Available from: https://www.un.org/millenniumgoals/

25. Fukuda-Parr S. Millennium Development Goals: Ideas, Interests and Influence. Taylor \& Francis; 2017. $274 \mathrm{p}$.

26. Mozambique [Internet]. SUN. [cited 2020 Apr 14]. Available from: https://scalingupnutrition.org/suncountries/mozambique/

27. Easterly W. How the Millennium Development Goals are Unfair to Africa. World Dev. 2009 Jan 1;37(1):26-35.

28. Mulaudzi FM, Phiri SS, Peu DM, Mataboge MLS, Ngunyulu NR, Mogale RS. Challenges experienced by South Africa in attaining Millennium Development Goals 4, 5 and 6. Afr J Prim Health Care Amp Fam Med. 2016;8(2):1-7.

29. McArthur HK and J. The world is off track to end hunger, so what's the solution? [Internet]. Brookings. 2017 [cited 2020 Apr 6]. Available from: https://www.brookings.edu/blog/future- 
development/2017/10/23/the-world-is-off-track-to-end-hunger-so-whats-the-solution/

30. SPRING. Nutrition Targets and Indicators for the Post-2015 Sustainable Development Goals: Accountability for the Measurement of Results in Nutrition [Internet]. SPRING. 2015 [cited 2020 Apr 20]. Available from: https://www.spring-nutrition.org/publications/resource-review/updates/nutritiontargets-and-indicators-post-2015-sustainable

31. Progress for Children report [Internet]. UNICEF DATA. 2015 [cited 2020 Apr 20]. Available from: https://data.unicef.org/resources/progress-children-report/

32. Narrowing the Gaps: The power of investing in the poorest children [Internet]. UNICEF. [cited $2020 \mathrm{Apr}$ 20]. Available from: https://www.unicef.org/publications/index_96534.html

33. Martin. The Sustainable Development Agenda [Internet]. United Nations Sustainable Development. [cited 2020 Apr 22]. Available from: https://www.un.org/sustainabledevelopment/developmentagenda/

34. Bhutta ZA, Ahmed T, Black RE, Cousens S, Dewey K, Giugliani E, et al. What works? Interventions for maternal and child undernutrition and survival. The Lancet. 2008 Feb 2;371(9610):417-40.

35. Strengthening Nutrition in Mozambique: A Report on FANTA Activities from 2012 to 2018. 2012;26.

36. Lazzerini M, Chhaganlal K, Macome AC, Putoto G. Nutritional services for children in Beira, Mozambique: a study reporting on participatory use of data to generate quality improvement recommendations. BMJ Open Qual. 2019;8(4):e000758.

\section{Figures}

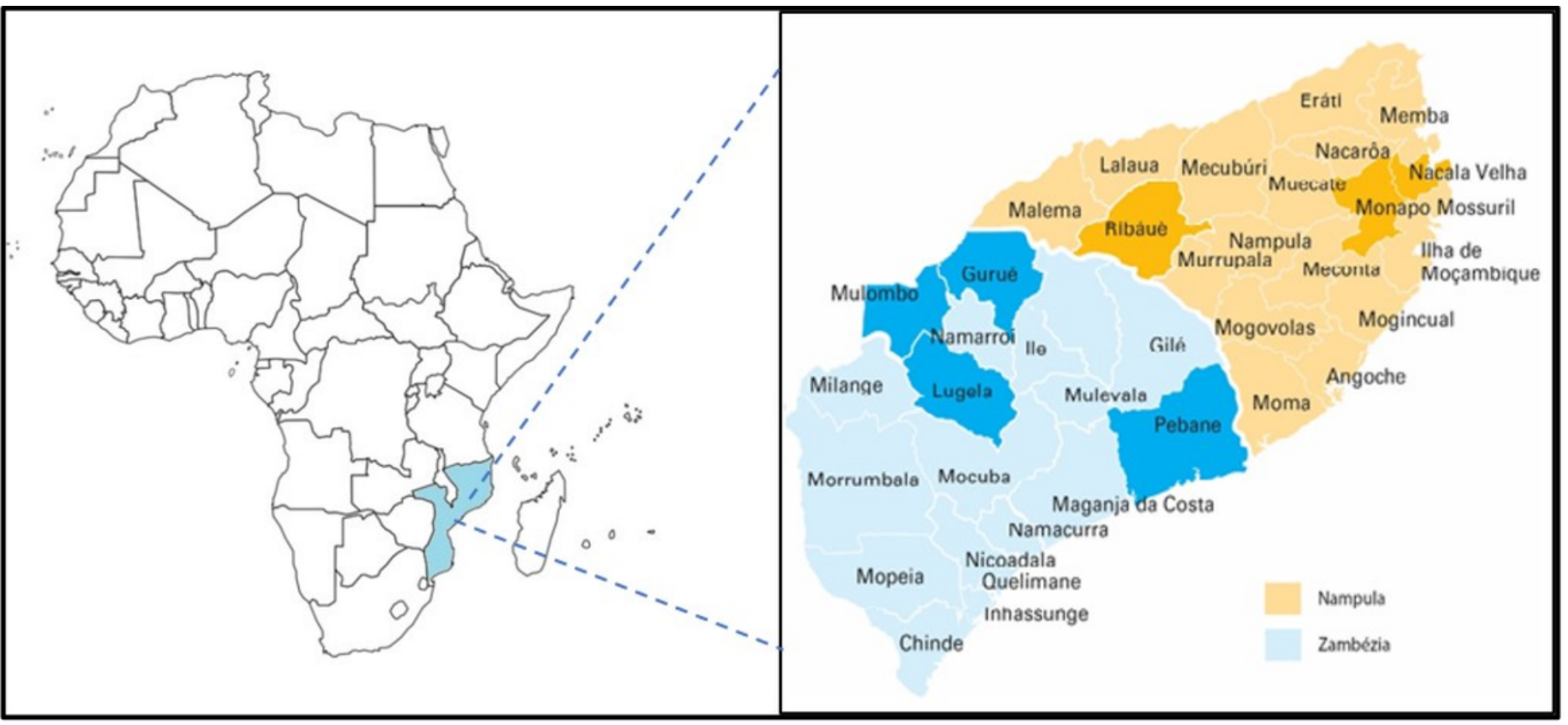

Figure 1

Map of Mozambique and survey districts within Zambézia and Nampula Provinces 


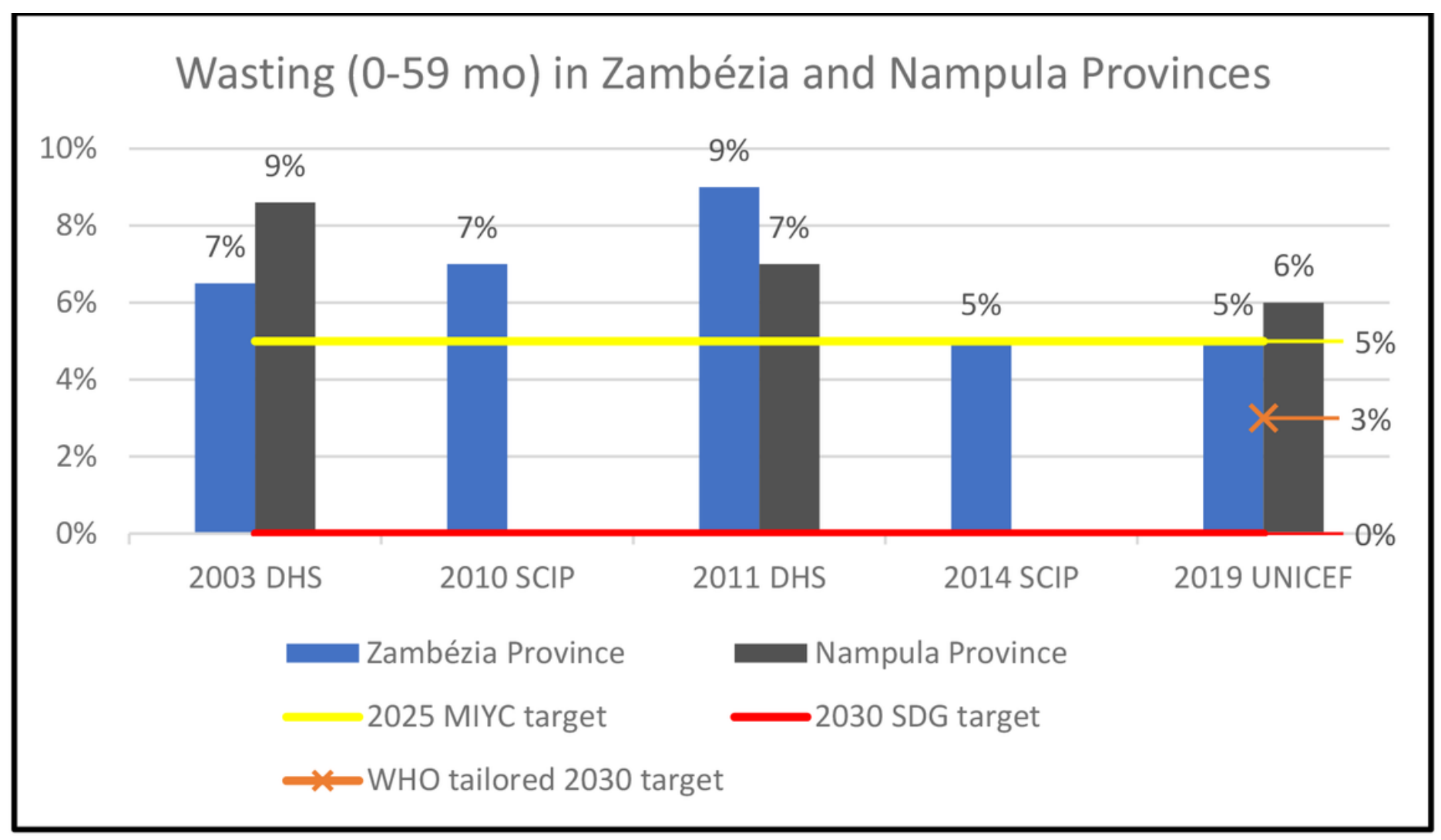

Figure 2

Wasting in children aged 0-59 months in Zambézia and Nampula Provinces, comparison across population-based surveys (inserted in Line 285 on page 16) Legend: DHS= Demographic Health Survey SCIP = Strengthening Communities through Integrated Programs SDG = Sustainable Development Goal MIYC = Maternal Infant and Young Child WHO = World Health Organization *Wasting measured using weight-for-length/height. 


\section{Stunting (0-59 mo) in Zambézia and Nampula Provinces}

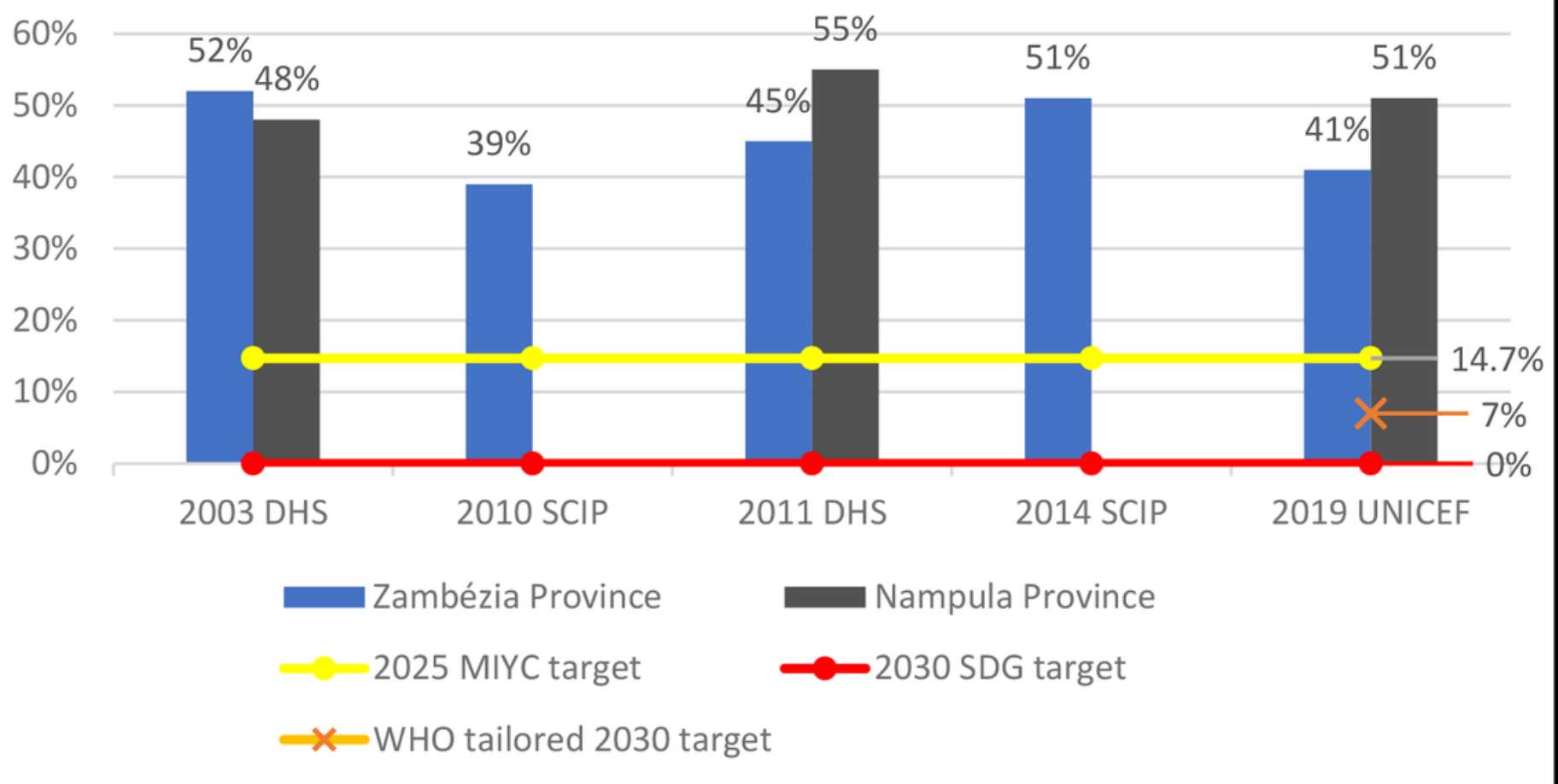

\section{Figure 3}

Stunting in children aged 0-59 months in Zambézia and Nampula Provinces, comparison across population-based surveys (inserted in Line 300 on page 17) Legend: DHS= Demographic Health Survey SCIP = Strengthening Communities through Integrated Programs SDG = Sustainable Development Goal MIYC $=$ Maternal Infant and Young Child WHO = World Health Organization 